\section{TRANSGRESIÓN Y COMPROMISO A PROPÓSITO DE JUDITH BUTLER Y SU RECEPCIÓN EN EL PENSAMIENTO FEMINISTA ESPAÑOL}

\author{
Elena Nájera \\ Universidad de Alicante \\ ORCID iD: https://orcid.org/0000-0001-8521-4160 \\ elena.najera@ua.es
}

Cómo citar este artículo/Citation: Nájera, E. (2020). Transgresión y compromiso a propósito de Judith Butler y su recepción en el pensamiento feminista español. Arbor, 196 (796): a557. https://doi.org/10.3989/arbor.2020.796n2009

\section{TRANSGRESSION AND COMMITMENT REGARDING JUDITH BUTLER AND HER RECEPTION IN SPANISH FEMINIST THOUGHT}

Copyright: (C) 2020 CSIC. Este es un artículo de acceso abierto distribuido bajo los términos de la licencia de uso y distribución Creative Commons Reconocimiento 4.0 Internacional (CC BY 4.0).

Recibido: 26 mayo 2018. Aceptado: 23 octubre 2019.

RESUMEN: El artículo aborda los conceptos de compromiso y transgresión en el marco de la lectura que el pensamiento feminista español de las últimas tres décadas hace de Judith Butler. Se parte de su teoría de la performatividad de género con el fin de valorar una primera serie de réplicas que acusan al programa de transgresión queer de sancionar una subjetividad acrítica que converge con el neoliberalismo. En un segundo paso, se precisa que el interés de esta autora en sus últimas obras se centra en las condiciones de la articulación de los sujetos colectivos, ofreciendo una concepción de la política como resistencia. En este punto se abre otra línea de discusión en las coordenadas del legado del feminismo de la igualdad sobre la capacidad del planteamiento de Butler de hacerse cargo de la agenda emancipatoria feminista y de su constitutivo compromiso ético-político.

PALABRAS CLAVE: Butler; pensamiento feminista español; subjetividad; queer; transgresión; compromiso; resistencia; feminismo de la igualdad.
ABSTRACT: This paper addresses the concepts of commitment and transgression in the framework of the interpretation that Spanish feminist thought has made of Judith Butler over the past three decades. First, her theory of performativity of gender is taken as a point of departure to evaluate the accusations that the queer transgression programme has endorsed an acritical subjectivity that dovetails with neoliberalism. Following this, it is stressed that the interest of Butler's most recent works lies in the conditions of articulation of collective subjects, offering a conception of politics as resistance. Here, another line of discussion is pursued vis-à-vis the legacy of egalitarian feminism revolving around the capacity of Butler's approach to deal with the emancipatory feminist agenda and its constituent ethical-political commitment.

KEYWORDS: Butler; Spanish feminist thought; subjectivity; queer; transgression; commitment; resistance; egalitarian feminism. 


\section{FEMINISMO Y SUBJETIVIDAD}

Las siguientes páginas se proponen una aproximación a los conceptos de compromiso y transgresión desde la discusión contemporánea en torno a la subjetividad, la identidad y el género. Se trata de un tema amplio que aquí se va a acotar a propósito de Judith Butler y de la lectura que se hace de su obra en el marco del pensamiento feminista español de las últimas tres décadas. Esta recepción se organiza sobre la herencia del debate entre el feminismo de la igualdad y el de la diferencia que ocupó intensamente los años ochenta de la pasada centuria ${ }^{1}$. Sin embargo, se ha de puntualizar desde el principio que, a pesar de que estas corrientes confrontaban dos concepciones distintas de las mujeres y sendas estrategias contra el sistema de dominación patriarcal, compartían la apelación a un sujeto colectivo declinado en femenino. Se interpelaba en ambos casos a un nosotras capaz de representar y asumir el objetivo común que fuere: extender derechos universales o crear otros nuevos a la medida de ese pronombre. El horizonte de los nuevos feminismos que recorren el siglo XXI presenta el contraste de una subjetividad irreductible a descriptores cerrados y renuente a las aspiraciones de unidad, incluida la que concierne al género (Gil, 2011, pp. 31 y ss.). En esta línea, priorizando el objetivo del reconocimiento de las diferencias sobre el de la distribución igualitaria, Butler representa ciertamente un giro en el imaginario feminista (Fraser, 2013/2015, pp. 19 y ss.). Su programa parte de una comprensión performativa de la identidad en la que la transgresión queer constituye un elemento vertebral que ha tenido un gran impacto en el análisis de los procesos de subjetivización.

Se comenzará precisamente por aquí, situando la posición butleriana, que se autoinscribe en la estela del feminismo socialista y se correlaciona con el proyecto de una democracia radical. Seguidamente, y en primer lugar, se atenderá a su repercusión más inmediata en el panorama español que alumbra un variado registro de propuestas que se apropian del rótulo queer. En torno a él y contra la subjetividad transgresora que nombra, se concentra asimismo una réplica que discute su capacidad para ofrecer un criterio consistente de la agencia política y contribuir a una teoría de la sociedad resolutiva contra el neoliberalismo. En segundo lugar, se puntualizará, no obstante, que esta autora, más allá de la teoría de la performatividad de género y su desarrollo queer, ha dedicado buena parte de sus últimos trabajos a establecer las condiciones constitutivas de los sujetos colectivos, perfilando la comprensión de la política en términos de "resisten- cia". Este concepto aspira a introducir un punto de vista normativo y a modular críticamente, en consecuencia, el ámbito de la transgresión. Sin embargo, aquí surge la cuestión de si esta aspiración, que pasa por la construcción de alianzas renunciando a convocar a las mujeres como un agente diferenciado y a dotar a su emancipación de una agenda específica, puede hacerse cargo de una noción de compromiso ético-político útil para el feminismo. Esta consideración llevará a cuestionar la propuesta de Butler y traerá a colación su controversia con Nancy Fraser, quien defiende de otra manera esa adscripción, que también hace suya, al patrimonio del feminismo socialista. En el contexto español, quienes asumen el legado del feminismo de la igualdad dan acuse de recibo de esta discusión subrayando la necesidad de afirmar estratégicamente una subjetividad compartida que no debe perder el hilo de su trayectoria reflexiva. Por ello mismo, frente a la deconstrucción que hace Butler de la historia del pensamiento feminista -acusado de haber ensombrecido las diferencias-, se reivindicará la productividad de su memoria crítica. La referencia obligada en este punto es el planteamiento de Celia Amorós.

\section{TRANSGRESIÓN QUEER}

La posición de Butler se sitúa en línea con el postestructuralismo y consiguientemente contra la concepción moderna de la subjetividad de factura cartesiana que hace de la autonomía un gesto soberano e incondicionado. Siguiendo a Michel Foucault $-y$ sin perder la inspiración nietzscheana, a la que se aludirá al final-, para esta autora el sujeto no puede comprenderse, sin embargo, al margen de las prácticas de poder, que no son solo ineludibles sino, en un sentido primario, generadoras de identidad. La fórmula althusseriana de interpelación ideológica le sirve igualmente para subrayar que el yo se construye de una manera heterónoma interiorizando las normas expresivas de un statu quo (Butler, 1997/2016, p. 12). Estas notas pasivas quedan recogidas en el término vínculo (attachment), que en The psychic life of power: theories in subjection (Mecanismos psíquicos del poder. Teorías sobre la sujeción) se califica como apasionado u obstinado (stubborn) para acentuar el apego del individuo a aquello que lo somete, pero a partir de lo que puede, en última instancia, articular una voz propia.

La cuestión es que ningún vínculo puede dar íntegramente cuenta de uno o una misma, pues no hay una única posibilidad de identificación o una identificación privilegiada que cubra o sature el contorno de la subjetividad. Esta se construye en contexto y 
por ello como una práctica repetitiva y reproductiva, pero también -puntualiza- "incompleta", puesto que admite una variación en el momento de la iteración y, por tanto, una oportunidad de reinterpretación (Butler, 1997/2016, p. 41). Butler contempla así el fracaso de la interpelación ideológica y la imposibilidad de absolutizar la sujeción, acentuando la capacidad de intervenir en la propia existencia -aunque esto no puede hacerse de una manera absoluta ni, como se precisará en el próximo epígrafe, estrictamente individual-. Se podría hablar así de un sujeto postsoberano, para el que no procede ya en ningún caso formular la autonomía a modo de una abstracta desvinculación, pero sí de un ejercicio de transgresión dentro de un marco de dominación compartido.

Conviene subrayar que el interés en pensar la agencia política es el que apremia a Butler a problematizar la noción de género de una manera ininterrumpida desde Gender trouble: feminism and the subversion of identity (El género en disputa. El feminismo y la subversión de la identidad) (1990) hasta Notes toward a performative theory of assembly (Cuerpos aliados y lucha política. Hacia una teoría performativa de la asamblea) (2015). Su preocupación no se centra tanto en la asimetría entre lo masculino y lo femenino derivada de la elaboración patriarcal de la diferencia sexual como en la generización en sí misma en tanto y cuanto sanciona, sea cual sea la pauta, determinadas categorías identitarias y distribuye en función de las mismas el reconocimiento y la falta del mismo, lo que induce a una precariedad diferenciada. Ciertos géneros se consideran inteligibles y sancionan la normalidad, ocasionando a su vez por ello marginación y exclusión, "fantasmas de discontinuidad e incoherencia" (Butler, 1990/2007, p. 72). Su contrapropuesta consiste en afirmar la performatividad del género: comprendiéndolo como una práctica indeterminada y plural que no está abocada a la mera reproducción de los patrones dominantes, pues la repetición de estos -su cita, en términos derridianos-, como ya se ha dicho, deja también un espacio para la resignificación y el desplazamiento (Butler, 2004/2006, p. 308). Este margen permite la introducción de una diferencia subversiva que pone en valor el alcance de la imaginación y de la fantasía que posee el sujeto, pues son estas facultades las que activan el deseo -otro deseo-y orientan una identificación alternativa. Como estrategia paradigmática de transgresión del modelo heteronormativo, Butler distingue la vía de la parodia presentándola como una imitación burlesca, hiperbólica y disonante que quedaría ejemplificada en el travestismo y en las acciones transgenéricas y transexuales (Butler, 1990/2007, p. 277).
El resultado de esta táctica deconstructiva con respecto a las normas de género preponderantes sería la disolución de cualquier identidad presuntamente natural, previa o estable; una confusión identitaria creadora, no obstante, de libertad en la medida en que permitiría la ampliación del mapa discursivo de la generización y, en definitiva, de las figuras posibles de la subjetividad (Butler, 1990/2007, pp. 96 y ss.; Butler, 2015/2017, p. 45). Este es el marco de la teoría queer que Butler contribuye decisivamente a definir -aunque su elaboración habría de remitirse también a otros nombres como el de Teresa de Lauretis-. Desde ella se hace eco de la acusación lanzada contra el feminismo hegemónico de raigambre ilustrada de enunciar un sujeto colectivo que no incluye las circunstancias raciales, de clase o de orientación sexual de muchas mujeres -además de responder a la crisis general de representación política que atraviesa las democracias contemporáneas-. Su impacto es notable en el panorama feminista español de la década de los noventa del siglo pasado.

En este contexto no puede hablarse de un movimiento queer unificado, sino más bien del surgimiento de grupos que activan este rótulo de manera variable, confiriéndole distintas versiones y un perímetro permeable que propicia el cruce entre activismos de contenido afectivo-sexual que también aúnan con frecuencia los intereses de grupos marginales de mujeres y hombres que se emplazan como ocupas, migrantes, explotados o insumisos (Gil, 2011, pp. 179 y ss.; López Penedo, 2008, pp. 115 y ss.). El registro de esta pluralidad de movimientos no es el objetivo de este trabajo, pero su alusión ilustra una condición importante para avanzar hacia las conclusiones: la dificultad que entraña la unificación de las experiencias de transgresión y la posible disolución entre ellas de las que deberían ser -si es que esta exigencia sigue vigente, como se discutirá más adelante-características del feminismo.

En paralelo, y a un nivel teórico, la rúbrica queer no garantiza un pensamiento unísono o sistemático -lo que, por otra parte, contradiría su propio talante-. Sin embargo, sí es posible reconocer un hilo discursivo que incide en la erosión del carácter normativo de la identidad y abre la subjetividad a un repertorio -inagotable e imprevisible- de posiciones. Las argumentaciones igualitaristas del feminismo clásico se vuelven en estas coordenadas improductivas y desechada resulta también la estrategia reivindicativa del feminismo de la diferencia que persiste en el binarismo de género. Desviándose, por lo tanto, de la impugnación del patriarcado que se llevaba a cabo en un itinerario o en otro, este 
programa se traza emblemáticamente en textos como los que firma Beatriz Preciado y que son citados con frecuencia en las revisiones más críticas (Posada Kubissa, 2015; Miguel, 2015). En su "Multitudes queer. Nota para una política de los "anormales»"2 esta autora reconstruye la genealogía filosófica del término -desde Foucault hasta Monique Wittig, Donna Haraway y Gloria Anzaldúa, pasando por supuesto por Butler-y lo utiliza, en efecto, para recusar tanto las políticas que se derivan de la diferencia sexual, entre las que cuenta las esencialistas y las paritarias, como las de inspiración republicana universalista. En la línea butleriana, Preciado presenta su propuesta como el resultado de una "confrontación reflexiva del feminismo con las diferencias que éste borraba" para poder homogeneizar y sujetar la conciencia colectiva (Preciado, 2003/2005, p. 165). Y acaba explicitando, por ello, su renuncia al objetivo de la emancipación de las mujeres en nombre de "una multitud de diferencias, una transversalidad de las relaciones de poder, una diversidad de las potencias de vida" que no son "representables" en la medida en que son "monstruosas" y ponen en cuestión por eso mismo "no sólo los regímenes de representación política sino también los sistemas de producción de saber científico de los «normales»" (Preciado, 2003/2005, p. 165). La reivindicación queer se concentra así en el cargo de exclusión y opresión que se imputa a los criterios identitarios tal y como han sido gestionados por la concepción del género hegemónica.

\subsection{Los límites de la transgresión}

Recorrido este tramo, cabe detenerse en su crítica, que constituye un capítulo central del pensamiento feminista español de las últimas décadas, desplegándose en diferentes direcciones. Una de ellas, que es la que aquí interesa ahora explorar, acusa -contra la pretensión butleriana de encarnar la izquierda- la coordinación de los planteamientos queer y de las políticas centradas en la inconmensurabilidad de las diferencias con el neoliberalismo, lo que desplaza el foco de la sospecha hacia la noción de transgresión. Ciertamente, procede hablar de una configuración neoliberal de la subjetividad que implica una reconfiguración de las normas de género (Fraser, 2013/2015, p. 13). Esta inflexión viene marcada por la creciente atomización del individuo de acuerdo con un modelo de autosuficiencia que reconduce y reduce la intersubjetividad al ejercicio de una libre competencia que se idealiza como expresión de igualdad. A su servicio, los entornos telemáticos y virtuales permiten multiplicar, al compás de la oferta y la demanda, los círculos de pertenencia y las posibilidades identitarias. La sensibilidad ética del mundo contemporáneo se mantiene de esta forma fiel a un ideario de la creación de sí que se presume al alcance de todos, cediendo al perspectivismo y tolerando una mirada relativista $-\mathrm{y}$ con frecuencia nihilista-. La vigencia de este escenario, que no está diseñado, por lo tanto, para facilitar el enlace político entre los sujetos, proporcionaría una explicación de las dificultades por las que atraviesa la construcción de imaginarios comunes, como el feminismo. Y también permitiría reconsiderar la transgresión queer como una producción indiscriminada, y sin contención normativa, de prácticas individualistas que no sirven para articular de una manera coherente ni eficaz una gramática colectiva antagonista. Subrayándose de este modo su rendimiento fundamentalmente estético y su colaboración en la fragmentación y desactivación del espacio público, cabría advertir la "deriva neoliberal" de la teoría queer (López Penedo, 2008, p. 243).

En un plano más concreto, y en el marco de la mercantilización y explotación de todas las dimensiones de la existencia, esta teoría se reprueba entonces como una manifestación del neoliberalismo sexual que se sustenta en una concepción acrítica de la autonomía. De acuerdo con esta, cualquier iniciativa que exprese una conformidad se considera válida e indicativa del valor del individuo. El programa queer confía en este sentido la transgresión a actuaciones presuntamente soberanas -olvidándose de los matices moderadores del prefijo post- que pueden poner, efectivamente, en cuestión la rigidez de las identidades, pero que no se detienen a considerar su capacidad ni calidad-subversiva ni su compatibilidad con según qué proyecto político (Miguel, 2015, pp. 137 y ss.). En definitiva, este activismo centrado de una manera reduccionista en la diversidad afectivo-sexual diluiría la causa feminista dejando intactos los esquemas de poder. Se sanciona así lo que Ana de Miguel ha denominado "patriarcados del consentimiento" en los que "el mito de la libre elección" bloquea la revisión del contexto de dominación que produce y reproduce los déficits de igualdad (Miguel, 2015, p. 11). La ideología neoliberal celebra, por tanto, la iniciativa individual "al tiempo que cierra los ojos ante las desigualdades estructurales laboriosamente descubiertas y cuestionadas durante décadas por los grupos subalternos, incluidos los feministas" (Fraser, 2013/2015, p. 13). Bajo esta mirada, la transgresión colaboraría en última instancia con la construcción de una subjetividad atomizada, estetizada y relativista que no interrumpe la lógica del mercado, que es la que consolida una distribución de recursos y derechos que no deja de poner en evidencia la feminización de sus asimetrías. 
La consecuencia es que se banaliza y opaca la comprensión de la igualdad. Pero esta es la clave normativa de la noción de compromiso congénita al feminismo. Como señala Fraser, las mujeres del siglo XXI se sitúan en una zona difícil e incómoda: en "el nexo entre patriarcado y neoliberalismo, atrapadas en dos formas de entender la igualdad, una liberal y otra democrática radical" (Fraser, 2013/2015, p. 13). A la luz de la primera acepción, se ha producido sin duda una depreciación de dicha clave frente a otras emparentadas con el ideario de la creación de sí, como podría ser la autenticidad asociada a la dinámica de la transgresión. Sin embargo, sorteando el falso dilema igualdaddiferencias -pues el antónimo del primer término es la desigualdad-, el debate es cómo ha de reorientarse el feminismo hacia la segunda acepción y si ha de perseverar como teoría crítica de la sociedad. Como se señalaba en la introducción, el horizonte político que quiere transitar Butler es también el de la democracia radical, reconociendo expresamente que uno de sus descriptores debe ser la igualdad. Esta, a su entender, tiene que reformularse, no obstante, como el resultado de una ampliación performativa de las categorías ético-políticas que no recaiga en la afirmación de una subjetividad estandarizada que frustre, volviéndolas impensables, otras vidas. El principio igualitarista resulta para esta autora insuficiente si no tiene en cuenta la precariedad que asignan las clasificaciones normativas (Butler, 2015/2017, p. 211). Para Fraser, en cambio, radicalizar la democracia exige compaginar -en una perspectiva bifocal- el reconocimiento de las identidades con la redistribución de recursos, derechos y representación con el fin de garantizar su simetría en lo que respecta a las mujeres.

Pensar en cualquier caso la versión de compromiso que conviene al feminismo implica abordar la cuestión de los sujetos colectivos. Butler introduce para ello la noción de "resistencia", cuyas posibilidades y límites han de medirse teniendo en cuenta la ontología de la contingencia a la que se adhiere. En el panorama español esta problemática se discute en las coordenadas del legado del feminismo de la igualdad.

\section{RESISTENCIA Y COMPROMISO}

En este punto, de cara a completar el análisis de la recepción del pensamiento de Butler, es preciso recordar que no se deja en ningún caso reducir a la teoría queer. Ella misma recalca que la teoría performativa de género es "sólo una parte" de su feminismo, matizando igualmente -lo que también conviene subrayar- que este es "sólo una parte" de su política.
"Creo" -se lamenta en la entrevista donde hace estas puntualizaciones- "que a veces se asocia el nombre de "Butler» con la afirmación de que el feminismo es o solo puede ser la teoría performativa de género, pero esta nunca ha sido mi posición" (Soley-Beltrán y Sabsay, 2012, p. 223). Como se indicaba al principio, esta autora ha empleado buena parte de sus últimos trabajos en reflexionar sobre las condiciones de la articulación de los sujetos colectivos. Este desarrollo es coherente con el programa de la transgresión, pero habilita -e incluso prioriza- un espacio reflexivo en torno a la normatividad que permite (re)plantear la noción de compromiso. Butler insiste en este sentido en que el horizonte ineludible de toda resignificación ha de ser el incremento de las vidas vivibles, lo que exige que la vulnerabilidad que nos define a todos y todas por igual -en tanto que seres corporales e interdependientes- no se resuelva en una precariedad diferenciada como la que inducen los esquemas socioeconómicos actuales. Este ha de ser el objetivo último de la política entendida como resistencia y orientar, como parte de la misma, las intervenciones que puedan hacerse desde el feminismo.

Contra la erosión neoliberal de la subjetividad, se trata, por lo tanto, de activar un "nosotros/as" antagonista que haga su aparición en la esfera pública y reivindique nuevos modos de existencia. Al igual que en el caso individual, para Butler no tiene sentido perfilar este pronombre antes de la misma acción performativa (Butler, 2015/2017, pp. 157 y ss.). Ello solo recogería la continuidad con un marco de dominación. De cara al desplazamiento, decir un "nosotros/ as" diferente puede crear a priori cierta concentración, pero a su entender solo cuando se produce un encuentro efectivo en una configuración particular de espacio y tiempo este sujeto en plural logra existir, aunque no esté explícitamente expresado. Su contorno lo traza de manera inmediata la manifestación de vulnerabilidad que implica una reunión de cuerpos. Pensar la política en el ámbito de lo precario, señala en este sentido, pasa por "movilizar la vulnerabilidad como una forma deliberada y activa de resistencia", por "una exposición del cuerpo al ámbito del poder en la acción colectiva" (Butler, 2015/2017, p. 185). Las prácticas de resistencia deben hacerse cargo de las dimensiones desamparadas de la vida en una determinada circunstancia y no pueden, por lo tanto, derivarse de la comprensión previa de una unidad ajustada a un agente abstracto que se presume general. Se organizan, por el contrario, a partir del ejercicio discursivo diferenciado que resulta de una acción siempre situada y que no consigue sino resolverse como un 
proceso contingente y por ello múltiple e inestable. El sujeto político, en resumidas cuentas, se construye de una manera asamblearia y, por lo tanto, mantiene un perímetro permanentemente abierto e inacabado que renuncia a representar una totalidad (Butler, 2015/2017, p. 64).

Habida cuenta de lo dicho, la posible ampliación, en principio irrestricta, del mapa de desplazamientos performativos, que podría hacer igualmente infinita la cartografía de la resistencia, obliga a marcar un criterio consistente con el horizonte normativo de la vida vivible. Esta es una cuestión -no siempre bien atendida por sus detractores- que la propia Butler tematiza recurrentemente, pero en los términos mínimos que permite su adhesión a una ontología de la contingencia que podría adjetivarse como insuficientemente modulada. Ella misma reconocía ya en Gender trouble -adelantándose en parte a la réplica que arriba se ha recogido-que la parodia por sí sola no es subversiva, pues en algunos casos resulta transformadora mientras que en otros se domestica y se vuelve a poner en circulación como instrumento de hegemonía cultural (Butler, 1990/2007, p. 270). Apremiando ahora la cuestión ética -sobre la estética-, advierte que los cuerpos activos congregados en la calle no suponen automáticamente una resistencia crítica. Hace falta determinar quién se levanta y dónde, pues insiste en observar que hay masas que no pueden merecer consideración, como las que toleren el racismo o el fascismo o la misoginia. Butler subraya que lo que le interesa "no es tanto la vitalidad de que gozan esas multitudes activas o cualquier fuerza naciente y prometedora de vida que parece pertenecer a la acción colectiva" como la lucha frente a la creciente y sistemática precariedad (Butler, 2015/2017, p. 184). Así pues, los criterios que deben permitir diferenciar unas resignificaciones de otras -como éticamente aceptables o no- no pueden derivarse de la práctica misma de la resignificación, sino de alguna teoría ya validada que ha de ser la de una democracia radical.

La pregunta se traslada entonces al contenido de esta teoría que, sin embargo, Butler no acaba nunca de concretar, haciéndolo girar en torno a la exigencia de transvalorar las categorías ético-políticas -como la de género- para hacerlas más inclusivas y, por tanto, más sensibles a lo que podría denominarse la fenomenología de la precariedad. Esta tendría que ocuparse de visibilizar, a su entender, "a mujeres, queers y personas transgénero, a los pobres, a los discapacitados y los apátridas, pero también a las minorías religiosas y raciales" (Butler, 2015/2017, p. 63). Su concepción de la política aspira a reconocer todas estas formas de opresión vigentes en las globalizadas sociedades tardocapitalistas y a facilitarles una vía subversiva. Pero en su esquema prima la insistencia en la imposibilidad de cerrar un criterio que permita discriminar de manera terminante entre las exclusiones y también entre las formas sociales alternativas. Puede que lo "correcto" -como ya se había apuntado en Undoing gendersea "mantener abiertas las tensiones que asedian las categorías más fundamentales que necesitamos..." (Butler, 2004/2006, p. 230).

Butler, en definitiva, no está dispuesta a cancelar la sospecha de sujeción, de reproducción de los mecanismos del poder, que le suscita cualquier punto de vista normativo que no sea la exigencia mínima de la vida vivible. Pero aquí se abre un espacio extenso de indefinición, puesto que esta prescripción renuncia a plegarse a un ideal uniforme. Pasa por cubrir las necesidades que permiten a un cuerpo subsistir, pero esto, dada la condición relacional y de interdependencia de la vulnerabilidad, implica un complejo sistema comunitario de apoyo, una forma social que no tiene una hechura única (Butler, 2015/2017, pp. 211 y ss.). Por ello, en esta filosofía de la resistencia el momento del antagonismo -que recusa un modo de vida mercantilizado que induce a una precariedad diferenciadaqueda más perfilado que el consiguiente momento afirmativo, que debería alumbrar un nuevo orden ligado a la aparición y el empoderamiento en el espacio público de otras subjetividades.

Butler sí que precisa que este último paso involucra la consolidación de vínculos en torno al denominador común de la precariedad. Esta, a su entender, funciona como "una condición social y económica" que trasciende los mapas culturales y atraviesa las distinciones identitarias, proporcionando un hilo ético-político para pensar "alianzas potenciales entre los que no se reconocen como miembros de una misma categoría" (Butler, 2015/2017, p. 63). Sin embargo, la ontología de la contingencia persistentemente accionada dificulta la concepción de estas alianzas y, por tanto, el diseño del compromiso feminista. En el marco de su controversia con Fraser, Butler desacredita terminantemente la retórica de la unidad que acusa en el planteamiento de su colega tachándola como propia de una izquierda conservadora que desatiende las diferencias -sexuales y sociales- y la lógica de la exclusión a la que responde la emergencia de las causas particulares. A su entender, la pretensión de aglutinar los movimientos sociales supondría su neutralización, su domesticación -llega a decir-. Butler rechaza, en- 
tonces, cualquier síntesis que implique la universalización o sistematización de los sujetos políticos desde la convicción de que "la resistencia a la unidad encierra la promesa democrática para la izquierda" (Butler, 1997/2001, p. 87). Su renuncia a hacer de la reconciliación un objetivo, incluso de manera provisional o estratégica, aspira a mantener la práctica contestataria permanentemente abierta, pero la expone a una improductividad nihilista en la que de nuevo solo queda implícitamente consensuada la oposición al marco hegemónico (Perona, 2017, p. 99).

En lo que respecta al feminismo del siglo XXI, su intervención de acuerdo con este punto de vista debería servir para entrelazar marcos de subyugación y resistencia antes que para mantener la prioridad y especificidad de la opresión femenina (Soley-Beltrán y Sabsay, 2012, p. 234). Esta causa por sí sola pierde entidad, quedando su eficacia asimismo remitida al espacio cruzado del antagonismo. Tampoco podría generar un relato convergente. La precariedad, como se ha puntualizado, afecta a las mujeres, pero esto no sería suficiente para justificar la afirmación de un sujeto colectivo estable, la construcción de un "sujeto global" declinado en femenino (Butler, $1990 / 2007$, p. 286). La teoría de la performatividad de género ha impugnado definitivamente la categoría "mujer" pudiendo rearticularse, como se ha visto, en diferentes direcciones, pero no sujetarse en torno a una clave diferenciada.

\section{1. ¿El sujeto del feminismo?}

Ante el riesgo de fuga del sujeto del feminismo, Fraser sí defiende que la generalización a propósito de las mujeres es necesaria. Desaprueba que Butler reemplace el lenguaje de la justicia social que ampara este gesto por un registro que elude el problema normativo al no poder ofrecer un criterio solvente para discriminar entre las posibles producciones y figuras de la subjetividad (Fraser, 1997/2016, p. 107). La "diferencia", como señala Celia Amorós coincidiendo con este planteamiento, "es un hecho que tiene lugar en las sociedades humanas y sólo si sufre las pertinentes contrastaciones puede ser promovida a valor" (Amorós, 2000, p. 49). En este sentido, ninguna pretensión de identidad ni propuesta de resistencia puede sortear la pregunta clave por su correlación con la desigualdad o su oposición a esta. Y ello es lo que mantiene vigente el compromiso específico del feminismo en la medida en que sigue siendo constatable una feminización de la desigualdad, de una de las formas características de la desigualdad que afecta a las mujeres frente a los hombres.
Dicha generalización es, por tanto, ineludible para proseguir con una agenda política resolutiva, aunque habría de someterse a una revisión frecuente para no recaer en exclusiones. Tendría que ajustarse a "conceptos de identidad social que sean plurales y de construcción compleja, y en los cuales el género fuera un hilo relevante entre otros, conceptos que prestaran atención a la clase, la raza, la etnicidad, la edad y la orientación sexual", variables que permiten visibilizar el cuadro de dificultades reales que atraviesan las diferentes mujeres (Fraser y Nicholson, 1992, p. 29; Guerra Palmero, 2001, p. 221). El discurso feminista ha de situarse y contemplar estas intersecciones con el fin de incorporar las voces de quienes no se sienten representadas en el discurso dominante, pero sin renunciar a la oportunidad política de ser un agente común. Se podría hablar así de una teoría feminista postmoderna que, superando el equívoco de la homogeneización, se despliega como "un tapiz compuesto con hilos de muchos colores" (Fraser y Nicholson, 1992, p. 30). Y en este complejo tejido el vocabulario normativo propio del feminismo ha de seguir sirviendo para explorar y denunciar ciertos marcos específicos de dominación. No podría en ningún caso cancelarse a favor de un lenguaje postfeminista -como el que gasta Butler, aunque con cierta vacilación como ahora se puntualizará- puesto que no se ha avanzado hacia una situación de post-patriarcado.

El programa de Fraser en este punto -aunque, si dispusiera en este trabajo de más espacio, mostraría mayores matices y contrastes- converge en nuestro contexto con el del feminismo de la igualdad enunciado emblemáticamente por Celia Amorós, quien insiste en la necesidad de seguir contando con ese nosotras como un sujeto político identificable. La pensadora española se sitúa en la tradición de las teorías críticas interesadas en hacer ver la subordinación específica que sufren las mujeres por el hecho de serlo para proceder a su irracionalización: "porque la propia tematización del sistema sexo-género como matriz que configura la identidad así como la inserción en lo real de hombres y mujeres es inseparable de su puesta en cuestión como sistema normativo" (Amorós, 2000, p. 98). Y ello le da entidad a la conciencia feminista, cuya experiencia reflexiva acusa la heterodesignación y se ejercita ciertamente en la resignificación y en la transgresión, pero desde la posición de ese pronombre en plural declinado en femenino cuyo criterio constitutivo es la vindicación de la igualdad. La aspiración a la emancipación no puede, por lo tanto, prescindir de una agencia común reformulada estratégicamente como "rúbrica articuladora de las diferentes modali- 
dades del sexismo que sufren las mujeres -violencia sexual, segregación en el mercado de trabajo, doble jornada laboral, infrarrepresentación en los puestos de responsabilidad, incongruencias en la adjudicación de estatus..." (Amorós, 1997, p. 358).

Así pues, asumiendo en este punto la reflexión de Seyla Benhabib, para Amorós solo sería pertinente considerar la muerte del sujeto en un sentido débil, como antídoto contra el fundamentalismo, pero nunca en un sentido fuerte que bloqueara la posibilidad de pensar conjuntamente la situación de dominación compartida y establecer vías emancipatorias colectivas (Amorós, 1997, p. 357). La propuesta de Butler reuniría, a su entender, la virtud del antiesencialismo y la de la superación de un modelo de sujeto abstracto y desvinculado. Sin embargo, no permitiría recuperar, como se ha indicado, el momento normativo de clave igualitarista que es el que consigue evidenciar el persistente marco de dominación patriarcal, por lo que acaba situándola fuera del paradigma del pensamiento crítico (Amorós, 2000, pp. 72 y ss.).

Con todo, en la recta final de estas páginas, convendría puntualizar que cuando se explora hasta el final el planteamiento de Butler se aprecia no solo la imposibilidad de reducirlo a la teoría queer, como se ha advertido, sino también su acercamiento -no exento de vacilación- al registro feminista clásico, que es el registro propio del feminismo de la igualdad. Sus objetivos se han ido reformulando en torno a un combate contra las diferentes formas de precariedad que debe aspirar a un cambio democrático alineado con la "posibilidad de una vida vivible para todos" (Butler, 2015/2017, p. 184). Así, conforme su reflexión se ha ido centrando en la vulnerabilidad, el léxico de la transgresión se ha acompasado al de la justicia. Como suscribe en Frames of war: when is life grievable? (Marcos de guerra. Las vidas lloradas) el reconocimiento de la precariedad compartida "introduce unos fuertes compromisos normativos de igualdad e invita a una universalización más enérgica de los derechos" (Butler, 2009/2010, p. 50). En estas coordenadas, su valoración del feminismo acusa cierta ambivalencia. En una entrevista antes citada se reivindica "muy feminista" y con la voluntad de seguir siéndolo "hasta que las mujeres no dejen de ser desproporcionadamente pobres y analfabetas y hasta que la violencia contra las mujeres cese y se llegue a la igualdad social" (Soley-Beltrán y Sabsay, 2012, p. 223). Sin embargo, a renglón seguido, concreta que no puede surgir una política suficiente a partir de la frase "soy una feminista" como tampoco de la frase "soy una feminista queer", puesto que las alianzas en las que ella deposita su confianza convierten esta causa en transversal. En cualquier caso, la resistencia, asumida como concepción política general, parece ser en este sentido compatible con el feminismo si este se entiende como un proyecto vigente, pero parcial e incompleto, cuya preeminencia como teoría crítica de la sociedad se disipa y cuyo alcance queda decisivamente limitado.

Aun así, se podría seguir intentando acortar algunas distancias dentro del espacio reflexivo de la historia del pensamiento feminista.

\section{A MODO DE APÉNDICE. LA CULTURA CRÍTICA DEL PENSAMIENTO FEMINISTA}

Neus Campillo considera que el nominalismo moderado que acoge el feminismo de Celia Amorós puede aproximarse coherentemente a la corriente feminista postmoderna en la medida en que uno y otra comparten en un sentido básico la desontologización de los términos abstractos, universales o genéricos (Campillo, 2010, p. 43). Desde otro lado, la afirmación de la contingencia a la que Butler se atiene podría encontrar cierto eco en el existencialismo de ascendencia sartreana de la pensadora española. Sin embargo, no es posible salvar una discontinuidad. La afirmación nominalista de la individualidad en Amorós se compagina con el reconocimiento de los efectos de poder que tiene en la esfera intersubjetiva la identidad de género, "la más cardinal y constrictiva de nuestras identidades" (Amorós, 1997, p. 30). Por ello, la autorrealización apremia a rearticular esa identidad contra la heterodesignación patriarcal. A su entender, la "concepción del sujeto idónea para el proyecto feminista" ha de apoyarse en la capacidad de trascendencia que es la que "posibilita que nunca nos identifiquemos por completo con nuestra identidad, que estemos permanentemente reinterpretándola y redefiniéndola" (Amorós, 1997, p. 30). La autonomía se desenvuelve, por lo tanto, en la contingencia, pero se decide normativamente en un sentido emancipatorio.

Butler insiste con un cierto aire de familia en que la reconstrucción de los posibles nosotros/as y también de sus vínculos ha de servir para forjar "un nuevo modo de vida más radicalmente democrático y más interdependiente" (Butler, 2015/2017, p. 218), pero su teoría de la performatividad no proporciona recursos para estabilizar y hacer operativo el compromiso que tales declaraciones implican y que ha de contar con la mediación específica del feminismo. Su ontología de la contingencia funciona, desde luego, como una garantía de pluralidad, aunque su vigencia ininterrumpida e insuficientemente modulada imposibilita 
el dibujo de los sujetos colectivos y un cierre resolutivo de las reivindicaciones. Aun así, no es fácil despachar el potencial crítico de la filosofía butleriana, que quizás pueda encajar después de todo en el largo y ancho proyecto feminista como una de sus piezas. Esta última digresión permitirá poner un punto y final.

En su Crítica de la razón patriarcal, Celia Amorós expuso de manera magistral cómo la filosofía se ha elaborado desde la complicidad con la ideología sexista, reproduciendo una determinada representación de la mujer y excluyéndola a su vez sistemáticamente de su discurso (Amorós, 1991, pp. 24-25). Sin embargo, también hizo ver que la propia tradición conceptual ha proporcionado una serie de instrumentos que no solo han servido a una comprensión conservadora de lo dado, sino también antagonista y subversiva. La ilustración está atravesada paradigmáticamente por esta dialéctica que es la que permite reciclar en un sentido feminista los presupuestos universalistas e igualitaristas que habían excluido originariamente a las mujeres del espacio de acción del sujeto moderno. Valorando los recursos contemporáneos, en su libro Salomón no era sabio la pensadora española dedica un capítulo a Nietzsche, quien, como se señalaba al principio, inspira la línea de pensamiento foucaultiana-butleriana. Su lectura permite concluir que la hermenéutica de la sospecha que pone en juego el método genealógico puede activarse -a pesar de las inflexiones misóginas del autor- contra cualquier modelo de legitimación, incluido el patriarcal (Amorós, 2014, pp. 142 y ss.). Se trata de una herramienta disponible entonces también, pese a no tener esa vocación, para los estudios de género.

En un sentido análogo, la propuesta butleriana también podría integrarse en la memoria crítica del pensamiento feminista. Y ello contra la propia Butler, quien se ha afanado en deconstruirla sin detenerse a medir sus aportaciones ni a apreciar la reinterpretación de los marcos de dominación a la que estas urgen. Sin embargo, teniéndolas en cuenta sí es posible reconstruir un relato de la modernidad alternativo al del falogocentrismo (Nájera, 2017). Como también ha de serlo completar una reseña de la postmodernidad que no reduzca todas sus voces a una suerte de idiocentrismo volcado en la exaltación compulsiva de las diferencias. En el caso que ha ocupado a este trabajo, esto último exigiría recorrer también la vía autocrítica que en el contexto español se abre dentro del propio ámbito del pensamiento queer (Burgos, 2014, pp. 71 y ss.). En ella la celebración del juego paródico cede paso al análisis de las condiciones de la resignificación: como son el poder y sus contextos -que delimitan de hecho el margen subversivo-, así como, en un sentido contrafáctico, ciertos principios éticos. De acuerdo con lo expuesto en estas páginas, Butler no asume de manera suficiente la modulación normativa de la contingencia, lo que deja desatendidas esas condiciones y, por lo tanto, resta operatividad a su propuesta. Su planteamiento puede integrarse, no obstante, como un elemento de ilustración -en su acepción de sospecha- en la amplia cultura del pensamiento feminista que no debe renunciar a articularse desde diferentes enfoques.

\section{AGRADECIMIENTOS}

Este trabajo ha sido realizado en el marco de los Proyectos I+D+i Género, compromiso y transgresión en España, 1890-2016 (FEM2016-76675-P) y Gobierno de sí y políticas de la subjetividad en el contexto de la crisis de la racionalidad neoliberal (FFI201676856-R), financiados por el Ministerio de Economía y Competitividad del Gobierno de España.

\section{NOTAS}

[1] En Nájera (2010) se recogen diferentes trabajos que discuten la relación entre el feminismo de la igualdad y el feminismo de la diferencia.

\section{BIBLIOGRAFÍA}

Amorós, C. (1991). Hacia una crítica de la razón patriarcal. Barcelona: Anthropos.

Amorós, C. (1997). Tiempo de feminismo. Sobre feminismo, proyecto ilustrado y postmodernidad. Madrid: Cátedra.

Amorós, C. (2000). Presentación (que intenta ser un esbozo del status questio-

[2] Este trabajo se publicó en 2003 en el número 12 de la revista Multitudes y fue recogido dos años después en Nombres. Revista de Filosofía. Cito por esta segunda publicación de 2005.

nis). En: Amorós, C. (ed.) Feminismo y filosofía. Madrid: Síntesis.

Amorós, C. (2014). Salomón no era sabio. Madrid: Editorial Fundamentos.

Burgos, E. (2014). La vida en las identidades. En: Suárez Briones, B. (ed.). Feminismos lesbianos y queer. Madrid: Plaza y Valdés.
Butler, J. (1990/2007). El género en disputa. El feminismo y la subversión de la identidad. Barcelona: Paidós.

Butler, J. (1997/2001). Mecanismos psíquicos del poder. Teorías sobre la sujeción. Madrid: Cátedra.

Butler, J. (1997/2016). El marxismo y lo meramente cultural. En: Butler J. y Fraser N. 
¿Reconocimiento o redistribución? Un debate entre marxismo y feminismo. Madrid: Traficantes de sueños, pp. 67-87.

Butler, J. (2004/2006). Deshacer el género. Barcelona: Paidós.

Butler, J. (2009/2010). Marcos de guerra. Las vidas lloradas. Barcelona: Paidós.

Butler, J. (2015/2017). Cuerpos aliados y lucha política. Hacia una teoría performativa de la asamblea. Barcelona: Paidós.

Campillo, N. (2010). El feminismo nominalista de Celia Amorós. En: López Fdez. Cao, M. y Posada Kubissa, C. (eds.). Pensar con Celia Amorós. Madrid: Editorial Fundamentos, pp. 37-44.

Fraser, N. (1997/2016). Heterosexismo, falta de reconocimiento y capitalismo. En: Butler J. y Fraser N. ¿Reconocimiento o redistribución? Un debate entre marxismo y feminismo. Madrid: Traficantes de sueños, pp. 89-107.

Fraser, N. (2013/2015). Fortunas del feminismo. Madrid: Traficantes de sueños.
Fraser, N. y Nicholson, L. (1992). Crítica social sin filosofía: un encuentro entre el feminismo y el posmodernismo. En: Nicholson, L. (ed.). Feminismo/posmodernismo. Buenos Aires: Feminaria, pp. 7-29.

Gil, S. L. (2011). Nuevos feminismos. Sentidos comunes en la dispersión. Madrid: Traficantes de sueños.

Guerra Palmero, M. J. (2001). Teoría feminista contemporánea. Madrid: Universidad Complutense de Madrid.

López Penedo, S. (2008). El laberinto queer. La identidad en tiempos de neoliberalismo. Madrid: Egales.

Miguel, A. de (2015). Neoliberalismo sexual. El mito de la libre elección. Madrid: Cátedra.

Nájera, E. (2010). ¿Feminismo de la igualdad y feminismo de la diferencia? Feminismo/s, 15, pp. 9-14. https://doi. org/10.14198/fem.2010.15.01

Nájera, E. (2017). La "capacidad feminista" de la filosofía cartesiana. Ingenium.
Revista Electrónica de Pensamiento Moderno y Metodología en Historia de las Ideas, 11, pp. 103-118. https://doi. org/10.5209/INGE.58304

Perona, A. J. (2017). La política como resistencia, la vulnerabilidad y algunos cabos sueltos. Isegoría. Revista de Filosofía Moral y Política, 56, pp. 89-108. https:// doi.org/10.3989/isegoria.2017.056.04

Posada Kubissa, L. (2015). Teoría queer, contexto español y crítica feminista. En: Posada Kubissa, L. Filosofía, crítica y (re) flexiones feministas. Madrid: Editorial Fundamentos, pp. 47-65.

Preciado, B. (2003/2005). Multitudes queer. Nota para una política de los "anormales». Nombres. Revista de Filosofía, 19 , pp. 157-166.

Soley-Beltrán, P. y Sabsay, L. (2012). Jugársela con el cuerpo. Entrevista con Judith Butler. En: Soley-Beltrán, P. y Sabsay, L. (eds.). Judith Butler en disputa. Lecturas sobre la performatividad. Barcelona: Egales, pp. 223-234 